mones are ...." A similar botanical definition is also given. Webster says of "hormone": "a specific organic product of living cells that, transported by body fluids or sap, produces a specific effect on the activity of cells remote from its point of origin". Quite comparably reasonable definitions, by all accounts.

Other reviewers would undoubtedly select other, perhaps more extensive, means of testing for accuracy and lucidity. My guess is that they would all find a few criticisms but that many of these arise because some termsmathematical ones, for example-are almost impossible to explain in the space of a dictionary definition.

The Chambers Dictionary of Science and Technology is by no means outstanding, but it is probably adequate for most of the uses to which it is likely to be put.

R. E. WoOdham

\section{Ehrenfest in Russia}

Paul Ehrenfest. By Victor Jakovlewitsch Frenkel (in Russian). Pp. 144. (Atomizdat: Moscow, 1971.) 2.5s; $\$ 0.28$.

THE first volume of Ehrenfest's biography, written by $\mathrm{M}$. J. Klein in English, was reviewed in Nature in 1970 (Nature, 228, 291; 1970). It seems appropriate to refer here to the independent biography by Frenkel, published a little later, which covers in a considerably smaller space the whole life of this remarkable theoretical physicist until his tragic death in 1933. Those who are masters of the Russian language will read this book with great interest and it would be most profitable for someone to translate it into English.

The reason that this book originated in the USSR is that Ehrenfest, whose scientific development started in Vienna and continued in Göttingen, met at the latter university his wife, Tatiana, a Russian mathematician, and they lived in Petersburg during the years 1907-12. Then, at the age of only 32 years, he became the successor of the great H. A. Lorentz as the sole professor of theoretical physics at Leyden. Obviously his work in Russia impressed those who influenced this selection, and Frenkel emphasizes especially an article on statistical mechanics published by Ehrenfest and his wife in the German Encyclopedia of Mathematical Sciences in 1911.

Ehrenfest's fame, however, was based less on his original research accomplishments than on his great ability to look critically at the contemporary problems and to present the results of his analysis both orally in his lectures and in writing in his publications and wide correspondence with the most out- standing physicists. Chapter 6 in Frenkel's book, entitled "Tell me who your friends are", reports on correspondence and personal encounters especially with Einstein and Bohr, whose differing views Ehrenfest attempted to reconcile.

Not less interesting is the last chapter 8 , "The work of the last years", with its emphasis on the history of the discovery of the spin of the electron in 1925 by Ehrenfest's young students Uhlenbeck and Goudsmit, who according to Frenkel owe much encouragement to their teacher.

This chapter ends with the analysis of Ehrenfest's state of deep depression which caused his many travels and, in spite of the warm reception encountered everywhere from his numerous friends, led finally to his voluntary end.

Two appendices (twenty pages of small print) to the attractive main text cover the topics "Statistical Mechanics" and "Ehrenfest's Adiabatic Invariants". K. FAJANS

\section{Deciding Factors}

Decision Theory and Human Behaviour. By Wayne Lee. Pp. $\mathrm{x}+352$. (Wiley: New York and London, October 1971.) $£ 6.15$.

To understand human decision-making must be one of the central goals of cognitive psychology. Decisions are ubiquitous components of psychological theories and of everyday experiencewhether it is the decision to press a button in a psychological laboratory or on a nuclear missile site, it is clear we stand to gain much from a fuller understanding of the principles and processes that are involved when man makes a decision.

Professor Lee has provided an outstandingly clear account of a wide range of topics in which decisionmaking plays an important role: studies of subjective probability, utility, gambling, probability learning, signal detection, sequential decision-making and games are all competently reviewed, and what is particularly impressive is the detailed treatment Professor Lee is able to provide without requiring any mathematical sophistication from his readers. Accordingly this book can be strongly recommended for advanced undergraduates and the non-specialist postgraduate.

In spite of the book's clarity, however, or perhaps precisely because of its clarity, it is difficult to avoid a slightly negative overall impression: for all their elegance, most theories that Lee reviews give a rather poor description of human behaviour. One reason for this is that such theories are somewhat isolated from the rest of psychology: decision theorists are apt to forget, for example, that gamblers have shortterm memory difficulties and lapses of attention like the rest of us. Until such information-processing limitations can be fully incorporated within a theory of decision-making, the decision theorist's world will continue to appear artificial. PHILIP T. SMITH

\section{Studies on Histamine}

The Biogenesis and Physiology of Histamine. By Georg Kahlson and Elsa Rosengren. Pp. 318. (Edward Arnold: London, October 1971.) $£ 6.50$.

THE strongest point of this book is the emphasis on newer concepts in histamine research, that is, that rates of histamine formation in tissues are of prime importance for evaluating its physiological function(s), that actions of endogenous non-mast cell histamine are neither antagonized by antihistamines nor accurately reproduced by injected histamine, and that new methods, mainly isotopic, are essential to further progress. The text is interesting and well written in Professor Kahlson's highly personal style. The volume was prepared by Kahlson and Dr Elsa Rosengren, an associate at the Institute of Physiology, University of Lund, Sweden, on invitation by the Monograph Committee of the British Physiological Society; it is an account of research on histamine by Kahlson, his colleagues and his students, in the authors' words, "The tale of a journey".

It is stated in the preface that "readers seeking information on a wide realm of histamine physiology will find our account narrow and unsatisfactory". Related work from other laboratories is included, however, so there is adequate coverage of many active research fronts.

The main subject is histamine formation and its relationship to gastric secretion, circulatory control, maintenance of homoeostasis, hypersensitivity, pregnancy, wound healing, malignant and regenerative growth, protein synthesis and seed germination. Methods for determination of histamine formation and effects of inhibitors and of hormones are included, as are chapters on histamine catabolism, brain histamine and a short discussion of mast cells.

Aspects of research on histamine omitted, or given only minor emphasis, are its chemistry, isolation from natural sources, methods not used by Kahlson's group, pharmacological actions, release, toxicity, tolerance and binding to proteins.

Kahlson and Rosengren cite 476 references, some as late as 1970 . The book is the only recent one in its field and is highly recommended for those interested in histamine research.

RICHARD W. SCHAYER 